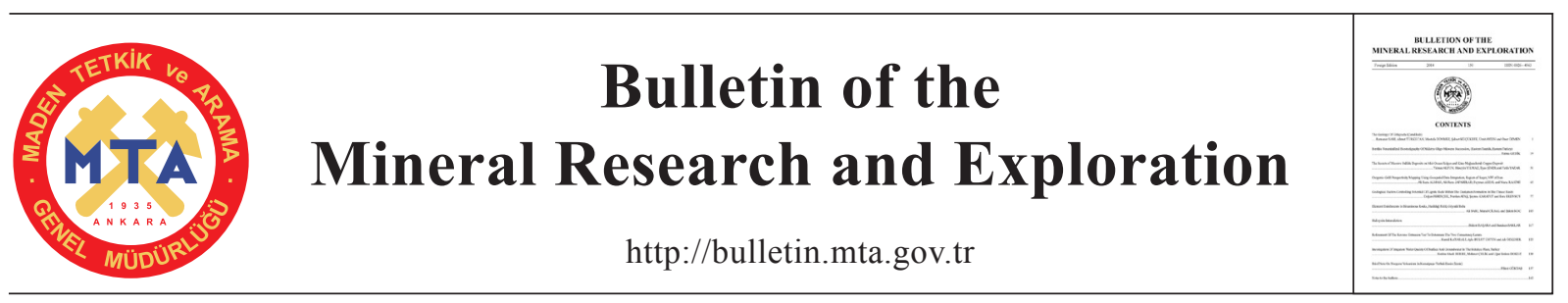

\title{
REFINEMENT OF THE REVERSE EXTRUSION TEST TO DETERMINE THE TWO CONSISTENCY LIMITS
}

\author{
Kamil KAYABALI ${ }^{\mathrm{a}^{*}}$, Ayla Bulut ÜSTÜN ${ }^{\mathrm{b}}$ and Ali ÖZKESER ${ }^{\mathrm{a}}$ \\ a Ankara Üniversitesi, Jeoloji Mühendisliği Bölümü, Ankara \\ ${ }^{b}$ Maden Tetkik ve Arama Enstitüsü Genel Müdürlüğ̈̈, Jeoloji Etütleri Dairesi Başkanlı̆̆l, Ankara.
}

Keywords:

Liquid Limit, Plastic

Limit, Fall-cone Method,

Rolling-Device Method,

Reverse Extrusion Test

\begin{abstract}
Liquid limit (LL) and plastic limit (PL) are the two most commonly used index properties of fine-grained soils. They have been used in not only classification of soils but also in correlation with certain engineering properties. Therefore, they have been subjected to numerous researches since they were first introduced by Atterberg in 1911. While their mechanisms were well defined in many codes and they have been in use for decades, criticisms often arose pertinent to the uncertainties inherent to them. Incredible amount of effort has been exerted to invent more rational testing methods in place of both the Casagrande's cup and bead rolling methods. Part of those efforts has been on devicing a single tool to measure the two relative index properties together. Recently, the reverse extrusion test was brought into the use of geotechnical engineers. It was shown that this tool has a potential of measuring LL, PL, and even the shrinkage limit (SL). The aim of this investigation is to reassess the ability of the reverse extrusion test to determine LL and PL with further refinement. In this regard 70 fine-grained soils covering a large range of plasticity were employed. Fall-cone method and rolling-device method were employed to determine LL and PL, respectively. The reverse extrusion tests were carried out at least five different water contents per soil sample. Extrusion pressures were plotted against water content and a curve fitting was applied to data pairs, from which the y-intercept (the coefficient a) and the slope (the coefficieent b) of the curve were determined. Those reverse extrusion coefficients were utilized to determine the representative extrusion pressures corresponding to LL and PL, as was done by the earlier researchers; however, the degree of success for the prediction of LL and PL using the representative extrusion pressures was not encouraging. Different from the previously proposed approaches, the reverse extrusion coefficients (i.e., a and b) were subjected to a multiple regression analysis along with the results of the conventional testing methods of fall-cone and rolling-device to determine the LL and PL as functions of the reverse extrusion parameters. It was shown that LL and PL can be predicted with a great degree of success using the reverse extrusion coefficients. While a great majority of the liquid limits found by using the fall-cone method were predicted with a $\pm 10 \%$ error, almost all of the plastic limits found by the rolling device were predicted with a $\pm 10 \%$ error. This refined investigation on the reverse extrusion test confirmed and proved that the reverse extrusion test is a simple, robust and inexpensive method capable of predicting both of two fundamental consistency limits using a single device.
\end{abstract}

\section{Introduction}

Atterberg limits namely liquid limit and plastic limit are the most commonly used and most easily defined index properties of fine-grained soils.
They were first proposed in 1911 by Atterberg for agricultural purposes to establish the range of moisture content of soils at the plastic phase (Casagrande, 1932). They determine interrelationships between the solid and liquid phases of soils. They have

\footnotetext{
* Corresponding author: Kamil Kayaball,kayabali@ankara.edu.tr
} 
been used extensively in classifying soils of similar mechanical properties. Whilest most researchers defined Atterberg limits as water holding capacity of soils, which is the basic physical meaning, another group of scientists considered them as critical states of undrained shear strength in terms of water content. The standardization of these limits for the purpose of soil classification were done by Casagrande (1932, 1958). Since then, these limits of consistence have been the focus of interest because they involve a number of uncertainties, they are defined by different equipments and, more importantly, they are not based on a rational basis for quantifying the consistency limits, particluarly the plastic limit.

The most common procedure for defining the liquid limit of a soil uses the Casagrande's cup test as currently defined in ASTM (2010) D4318-10. In this test, a brass cup is raised by a snail-shaped cam and then dropped from a distance of $10 \mathrm{~mm}$ onto a rubber base. The soil sample in the brass cup is grooved by special tool and the liquid limit is defined as the water content corresponding to 25 blows to close groove for a length of $13 \mathrm{~mm}$. Because the chances are very low to catch the 25 blows at first attempt, the test is repeated several times at different water contents each having a different number of blows. A semilogaritmic plot is constructed with the water content is on the linear axis and the number of blows is on the logarithmic axis. A straight curve is fitted to the data points and the water content corresponding to 25 blows is read off. The liquid limit is the water content of a soil when 25 blows cause $13 \mathrm{~mm}$ of closure of the groove at the base of the cup.

The uncertainties and/or the factors affecting the results of Casagrandes's cup method have been addressed as (Johnston and Strom, 1968; Wroth and Wood, 1978; Whyte, 1982; Clayton et al., 1995; Lee and Freeman, 2007; Haigh, 2012):

1) The hardness of the base of the apparatus (i.e. hard rubber in ASTM D4318 versus soft rubber in British Standards),

2) Physical properties of the bench on which the Casagrande's cup stands,

3) Changes in drop height due to lacking of regular calibration of the drop height,

4) The performance of the operator,

5) The tendency of halves to slide together,

6) The migration of water in dilatant soils,
7) Incorrect frequency of drops,

8) Soil type,

9) Use of worn grooving tools,

10) Incorrect forming of soil groove,

11) Dynamic effects inherent to the equipment.

The range of results reported for Casagrande's cup method is rather alarming, particularly in view of the fact that it was known by the participating organizations that their results would be compared with those of rival organizations. Sherwood (1970) commented that Transport and Road Research Laboratory (UK) attempts to assess the amount of error attributable to defective or worn apparatus in the liquid limit test indicated that majority of error was due to operator technique (Clayton et al., 1995). It was reported that the incorrect frequency of drops caused some $15 \%$ moisture content error in determining the liquid limit using the Casagrande's cup method (Clayton et al., 1995).

The test has been carried out worldwide with little variations from that proposed by Casagrande. For instance, while ASTM D4318 standard utilized hard rubber base, the British and Indian codes still enforces the use a soft rubber base. The grooving tool used in this test also comes two variants in ASTM and AASHTO. While the one by AASHTO yields unsatisfactory grooves, its use nevertheless persisted (Haigh, 2012).

Plastic limit was defined by Atterberg as the water content at which the soil paste cannot be rolled into a thread (Casagrande, 1932). This method requires a soil mass to be rolled into a thread by hand with a specified pressure. The moisture content, expressed as a percentage of the weight of oven dried soil at which the soil mass begins to crumble when rolled into a thread of about $3 \mathrm{~mm}$ is defined as the plastic limit. Commonly known as the "bead rolling" test, this procedure has the following uncertainties and/or factors affecting the plastic limit test results (Whyte, 1982; Sivakumar et al., 2009):

1) The pressure applied to the soil bead,

2) The geometry (e.g. width of the hand contact to bead diameter),

3) The friction between the soil, hand, and base plate,

4) The speed of rolling, 
5) The risk of contaminating the soil sample,

6) The vagueness of the guidelines on the test.

The amount of finger pressure used and the shape of the fingers varies to a great extent and, in addition, operators frequently do not perform the test using the tips of the fingers since these are eminently suited to the task (Clayton et al., 1995). Even if the test is performed by strictly following the guidelines specified in the related codes, its repeatability by the same operator and reproducibility amongst different agencies are low because it does not include a commonly accepted quantifiable procedure. For instance, because the operator visually inspects the diameter of the thread at the time of crumbling and usually uses no caliper to measure it, small variations in the diameter of the thread may cause considerable differences on the resulting PL value, which in turn may result in a different level of plasticity for the same soil or in a major shift from silt to clay or viceversa.

Regarding a number of limitations of the Casagrande's cup method outlined above, many researchers proposed the use of the fall-cone method to determine the liquid limit (Sherwood and Ryley, 1970; Wood, 1982; Belviso et al., 1985; Wasti and Bezirci, 1986) and the same has been included in several national codes of practice such as British standars (BSI, 1990), Canadian standards (CAN/ BNQ, 1986) and Indian standards (ISI, 1985) (Prakash and Sridharan, 2006). In spite of the main advantages of fall-cone test such as simplicity, ease of operation and comparative reproducability, the American Society for Testing and Materials (ASTM), one of the worldwide used standards, has not included the fallcone method (Prakash and Sridharan, 2006). Attempts have been made so that the fall-cone can be employed to determine the plastic limit as well (e.g. Belviso et al., 1985; Prakash and Sridharan, 2006; Lee and Freeman, 2007). Lee and Freeman (2007) compared eight non-ASTM test methods to the Casagrands's cup liquid limit method and did the same for ten non-ASTM alternatives to the bead-rolling plastic limit method on three cohesive soils. They reported that only one non-ASTM method (i.e. the unified or "dual-weight" fall-cone apparatus) yield within 10\% of the ASTM liquid and plastic limit values.

One of the attempts for devising a single tool capable of determining both consistency limits is the development of soil extrusion test. Extrusion is a technique whereby materials such as metals, plastics or food stuff are induced to flow plastically through a die by a ram (Medhat and Whyte, 1986). It was first brought into attention by Timar (1974) who was able to have partial success to determine the most common two Atterberg limits (i.e., LL and PL) using the direct extrusion method. Difficulties were reported in interpreting the results due to the influence of friction as the billet is forced along the container of the die. Whyte (1982) first used the reverse extrusion test in soil mechanics extensively. He reported that the reverse extrusion technique is a reliable method for determining soil plasticity that promises to be rapid, simple and economical. Medhat and Whyte (1986) extended the use of the reverse extrusion test to relate the shear strength to extrusion pressures. They obtained plastic limit values with a reasonable repeatability and reported that the reverse extrusion method appears to offer potential as an index test method.

In an attempt to determine the most common two consistency limits using the same and less operatordependent instrument, Kayabalı and Tüfenkçi (2007) employed the reverse extrusion test by following the guidelines outlined by Whyte (1982). For the twenty soils they tested, they set two extrusion pressures of $2250 \mathrm{kPa}$ and $30 \mathrm{kPa}$ for the plastic limit and liquid limit, respectively. Kayabalı and Tüfenkçi (2010) further refined the reverse extrusion test to determine consistency limits. They determined plastic limit and liquid limit as the water contents corresponding to the extrusion pressures of $3000 \mathrm{kPa}$ and $35 \mathrm{kPa}$, respectively, based upon tests performed on 30 soil samples. Kayabalı (2012), based on about some 4000 consistency tests on 100 soils with different levels of plasticity, determined that the liquid limit, plastic limit and the shrinkage limits are the water contents corresponding to the extrusion pressures of $20 \mathrm{kPa}$, $2000 \mathrm{kPa}$ and $12000 \mathrm{kPa}$, respectively.

Research conducted by the senior author (i.e., Kayabali and Tüfenkçi, 2007; Kayabalı and Tüfenkçi, 2010 and Kayabal1, 2012) reveals that the extrusion pressures corresponding to liquid an plastic limits are not unique.

Therefore, the determination of consistency limits as the water contents corresponding to the certain values of the extrusion pressure does not appear to be a viable approach. Nevertheless, the potential of the reverse extrusion test to determine the consistency limits can be addressed using a different analysis method.

The scope of this investigation is two-folds: 1) Re-examination of the relation between the results of the reverse extrusion test and those of the consistency 
limits by testing a new set of soil data representing a reasonably large range of soil plasticity. 2) Introduction of an alternative method and comparison between the methodology previously employed by the senior author and the newly proposed statistical approach.

\section{Materials}

As part of the evaluation of the consistency limits via the reverse extrusion test 70 fine-grained soil samples were prepared. Because an investigation such a present study needs to cover a range of plasticity as wide as possible, the soil samples used for the investigation were prepared in the laboratory. The difficulty of obtaining a number of natural soil samples covering a large range of plasticity should be appreciated. Accordingly, the test materials were prepared using the mixtures of a natural soil sample with fine-grained sand and commercially available bentonite. The natural soil sample had a liquid limit and plastic limit of 54 and 26, respectively. In order to obtain soil samples of lower liquid limits than 54 , a fine-grained sand sieved through a \#40 mesh was added to the natural sample at varying proportions. A similar procedure was applied to obtain soil samples with higher liquid limits than 54 by adding commercial bentonite to the natural soil at certain increments. This way, a series of soil samples were constituted whose liquid limit ranged from 29 to 105 . It should be noted that the natural soil samples was oven-dried, pulverized and sieved through \#40 mesh prior to mixing with fine sand and bentonite.

\section{Methods}

The testing methods employed for this investigation include the fall-cone, the rolling-device and the reverse extrusion. Whilest the Casagrande's percussion method is a more common method than the fall-cone test, it has long been recognized that the Casagrande liquid limit test is not very repeatable. In contrast, the fall-cone test has been shown to give a much lower standard deviation of the results than the cup test when identical samples are tested at multiple laboratories (Sherwood, 1970; Haigh, 2012). Upon this fact, the fall-cone method was selected to determine the liquid limit of soil samples. The setup employed for this purpose has a cone of $80 \mathrm{~g}$ mass and a cone angle of 30 degrees. The wet soil sample with a moisture content somewhat higher than its liquid limit was first homogeneously mixed and placed into the container of the setup with a smoothly leveled surface. The cone was released and let it penetrate into the specimen for 5 seconds. It was ensured that there was zero air gap between the tip of the cone and the upper surface of the specimen. The depth of penetration of the cone was measured by a digital gage. Following this, the moisture content of the specimen was determined. The second specimen was prepared in a manner so that the mositure content was higher than the previous stage. The specimen was homogeneously mixed again and subjected to cone penetration. Another moisture content determination was performed and this process was repeated on several specimens with different water contents. The cone penetration versus water content data were plotted on a linear graph and the water content corresponding to the penetration depth of $20 \mathrm{~mm}$ was determined as the liquid limit of the soil sample.

As for the plastic limit test the rolling-device shown in figure 1 was utilized. While the common practice has long been the employment of hand rolling of a soil bead, introduction of a rolling-device and thus further standardization of the plastic limit eliminated some of the uncertainties pertinent to the performance of the plastic limit test by bead rolling by hand. In this test the top and bottom plates have smooth unglazed paper attached to them against sticking of the soil bead to those plates. The soil bead is placed between these two plates and the top plate is moved back and forth with a slight pressure. This action is continued until the top plate comes to contact with the side rails, which are $3.2 \mathrm{~mm}$ higher than the base plane of the bottom plate. The plastic limit is determined as the water content when the thread of soil breaks into a series of cylynder-shaped pieces about 3.2 to $9.5 \mathrm{~mm}$ in length. This process is repeated for at least three times and the average water content is fixed as the plastic limit.

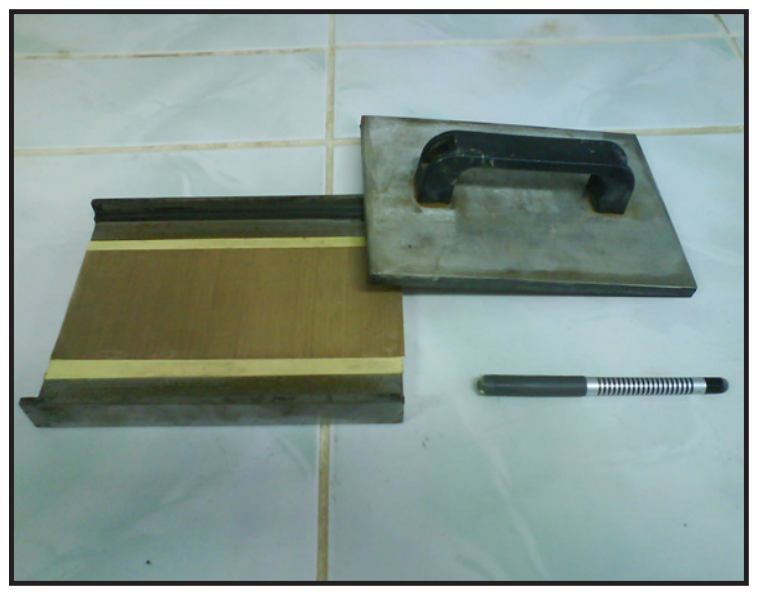

Figure 1- The rolling-device used to determine the plastic limit of soil samples. 
The testing apparatus used for the reverse extrusion test is mainly composed of a container and a rammer (Figure 2). The inner diameter of container

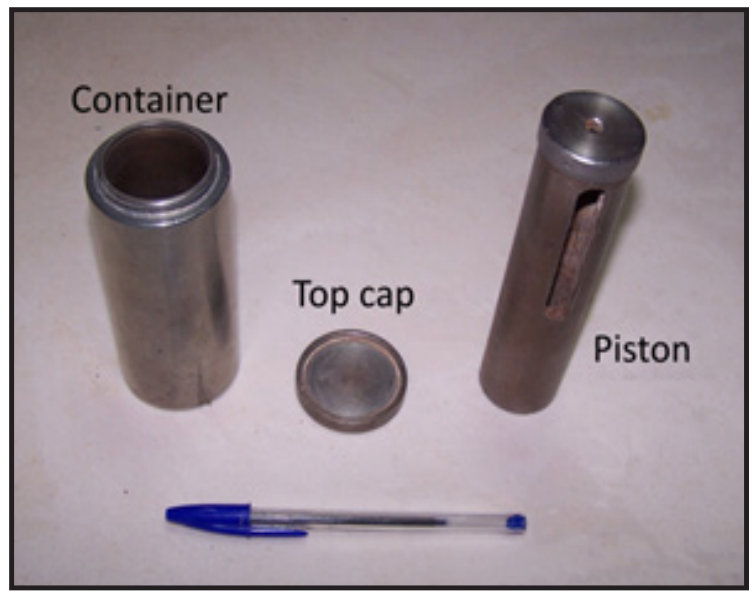

Figure 2- The reverse extrusion apparatus.

is $38 \mathrm{~mm}$ and its height is $150 \mathrm{~mm}$. The rammer has a die orifice of $6 \mathrm{~mm}$ in the middle. There is a clearance of $0.2 \mathrm{~mm}$ between the rammer and the inner surface of the container. Oven-dried, pulverized and sieved soil sample of about $150 \mathrm{~g}$ is required for this test. Approximately $100 \mathrm{~g}$ of soil specimen is first wetted by an amount of water slightly lower than its liquid limit and mixed homogeneously. The wet mixture is divided into a few chunks of about the same size. Each chunk is then dropped into the container and tapped with a piston. This way, all chunks of wet soil are filled into the container somewhat in a compacted manner to ensure that there is not large vugs in between. Then, the rammer is driven into the container, which are placed together in a uniaxial load frame with a digital load cell. The soil inside the container is loaded at a rate of $1 \mathrm{~mm} / \mathrm{min}$ and the compression force is recorded. The soil is compressed until it fails in the form of soil worm as shown in figure 3. The compression force continues to increase until the compressed soil extrudes from the die orifice and then becomes steady as shown in figure 4, which consists of 5 experimental curves, each obtained at different water contents. The flat portion of curves in figure 4 corresponds to the extrusion pressures at failure, which are then plotted in a semilogarithmic graph against water content. A sample graph is shown in figure 5. The logarithm of extrusion pressure versus the water content results in a perfectly linear relationship. An attempt to investigate the operator dependence of the reverse extrusion test by employing several unexperienced people revealed that the test is not operator dependent and eliminates many uncertainties pertinent to Casagrande's cup liquid limit and bead-rolling techniques.

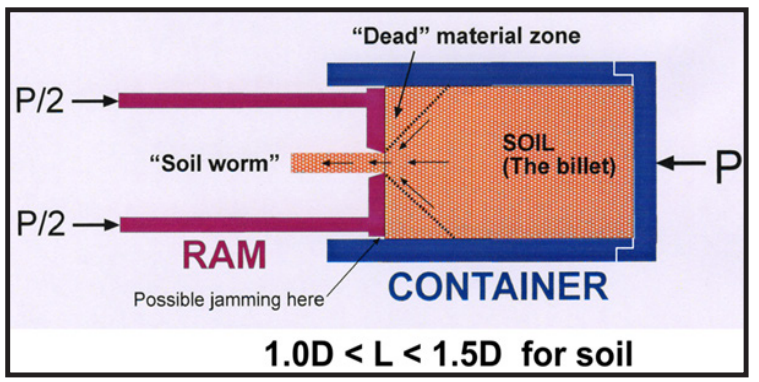

Figure 3- Schemmatical illustration of how the reverse extrusion method works ( $\mathrm{L}=$ the length and $\mathrm{D}=$ the diameter of the soil billet).

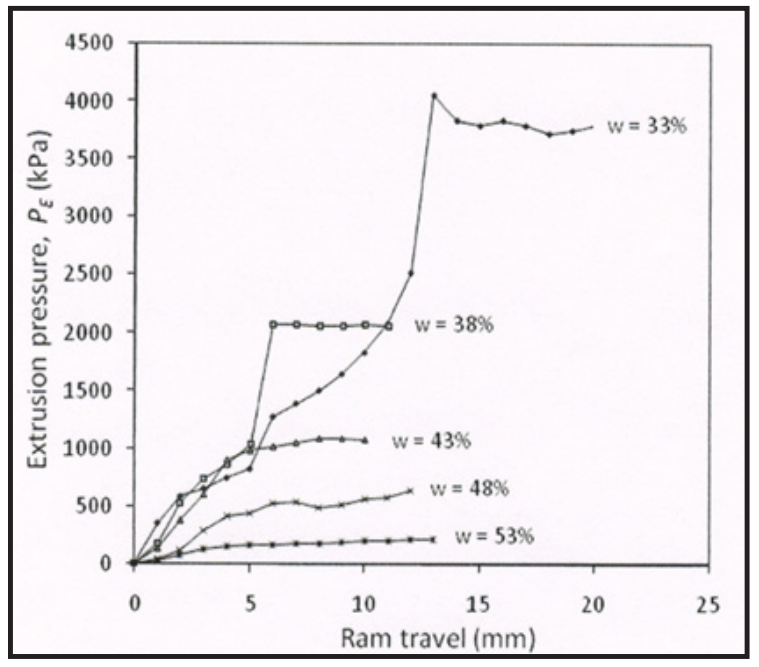

Figure 4- Reverse extrusion test results for different water contents. The flat portion of curves develops after the soil worm forms.

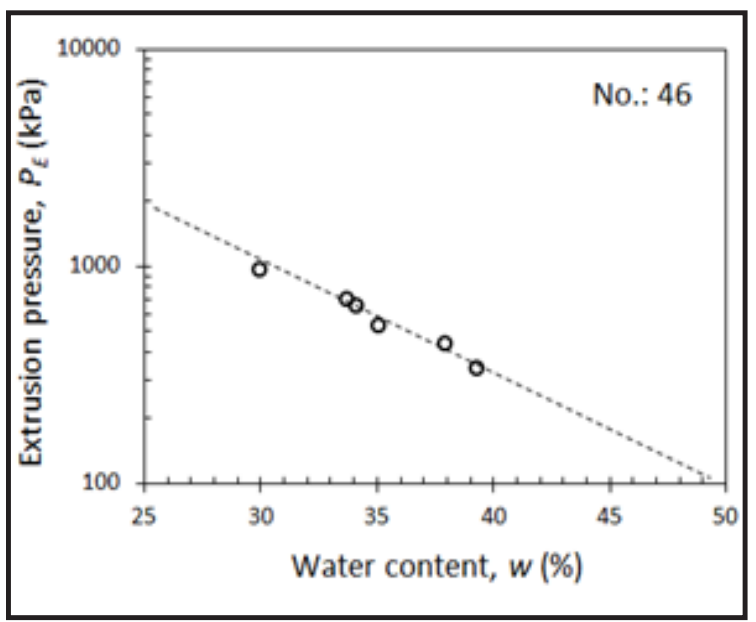

Figure 5- Example plot for the extrusion pressures at failure versus water contents. 


\section{Results and Discussion}

A comprehensive laboratory experiment program was followed towards predicting the two fundamental consistency limits of fine-grained soils. To determine the liquid limits of soil samples, at least five data pairs of cone penetration depth versus water content were constituted. The overall results obtained from the fall- cone liquid limit tests are given in table 1 for 70 soil samples.

Concerning the plastic limits of the same set of samples, the rolling-device method was employed as explained before. The plastic limit tests were repeated 5 times for each soil sample and the averages were taken and listed in table 1.

Table 1- The liquid limits determined using the fall-cone method, the plastic limits determined using the rolling device method, and the reverse extrusion coefficients for 70 fine-grained soils used in this investigation.

\begin{tabular}{|c|c|c|c|c|c|c|c|c|c|}
\hline No. & LL & PL & a & b & No. & LL & PL & a & b \\
\hline 1 & 29.3 & 16.9 & 6.07 & 6.7 & 36 & 51.5 & 26.3 & 5.25 & 13.8 \\
\hline 2 & 30.7 & 16.4 & 5.97 & 6.9 & 37 & 51.5 & 23.8 & 5.61 & 11.5 \\
\hline 3 & 30.8 & 15.4 & 5.96 & 6.9 & 38 & 53.2 & 23.6 & 5.25 & 13.8 \\
\hline 4 & 31.6 & 16.5 & 6.01 & 6.8 & 39 & 53.5 & 25.6 & 5.30 & 13.5 \\
\hline 5 & 32.2 & 16.9 & 5.85 & 7.5 & 40 & 53.5 & 25.8 & 5.53 & 12.0 \\
\hline 6 & 32.2 & 18.1 & 5.86 & 7.2 & 41 & 54.5 & 25.3 & 5.17 & 14.1 \\
\hline 7 & 32.9 & 17.3 & 5.15 & 9.9 & 42 & 55.0 & 23.9 & 4.68 & 18.3 \\
\hline 8 & 33.2 & 17.2 & 5.85 & 7.5 & 43 & 55.0 & 24.9 & 5.03 & 15.0 \\
\hline 9 & 33.5 & 18.1 & 5.86 & 7.6 & 44 & 55.9 & 26.0 & 4.67 & 18.7 \\
\hline 10 & 34.5 & 18.6 & 6.03 & 7.4 & 45 & 57.5 & 25.4 & 4.88 & 16.5 \\
\hline 11 & 35.2 & 18.3 & 6.08 & 7.4 & 46 & 59.4 & 25.5 & 4.56 & 19.3 \\
\hline 12 & 35.3 & 18.0 & 5.53 & 8.7 & 47 & 60.5 & 24.7 & 5.14 & 15.3 \\
\hline 13 & 36.8 & 18.9 & 5.74 & 8.5 & 48 & 62.0 & 26.0 & 4.94 & 17.0 \\
\hline 14 & 37.0 & 17.8 & 5.88 & 8.3 & 49 & 62.8 & 25.3 & 4.64 & 19.3 \\
\hline 15 & 37.2 & 19.1 & 5.30 & 10.2 & 50 & 63.0 & 24.4 & 4.79 & 17.8 \\
\hline 16 & 37.8 & 19.5 & 5.51 & 9.5 & 51 & 65.0 & 26.5 & 5.08 & 15.7 \\
\hline 17 & 39.0 & 19.5 & 5.69 & 9.3 & 52 & 67.0 & 26.1 & 4.67 & 18.9 \\
\hline 18 & 40.3 & 19.1 & 5.79 & 8.9 & 53 & 69.0 & 24.4 & 4.99 & 16.4 \\
\hline 19 & 41.2 & 21.0 & 5.53 & 10.0 & 54 & 69.5 & 25.9 & 4.89 & 17.3 \\
\hline 20 & 42.0 & 20.0 & 5.34 & 10.6 & 55 & 72.0 & 25.7 & 4.60 & 20.2 \\
\hline 21 & 42.2 & 21.3 & 5.73 & 9.3 & 56 & 75.0 & 26.4 & 4.91 & 17.4 \\
\hline 22 & 42.4 & 21.6 & 5.64 & 9.5 & 57 & 77.0 & 26.9 & 4.57 & 21.0 \\
\hline 23 & 43.5 & 21.8 & 4.93 & 13.3 & 58 & 79.5 & 26.4 & 4.83 & 18.0 \\
\hline 24 & 44.0 & 21.0 & 6.37 & 7.9 & 59 & 80.0 & 27.8 & 4.68 & 19.8 \\
\hline 25 & 44.2 & 23.2 & 5.34 & 11.6 & 60 & 83.0 & 27.3 & 4.95 & 17.1 \\
\hline 26 & 44.5 & 23.0 & 5.52 & 11.5 & 61 & 84.0 & 26.7 & 4.80 & 18.4 \\
\hline 27 & 44.8 & 20.7 & 5.18 & 11.5 & 62 & 84.5 & 26.1 & 4.59 & 20.7 \\
\hline 28 & 45.0 & 23.4 & 6.00 & 9.0 & 63 & 88.5 & 26.7 & 4.78 & 18.2 \\
\hline 29 & 45.3 & 22.8 & 5.64 & 10.7 & 64 & 90.5 & 27.8 & 4.39 & 23.3 \\
\hline 30 & 45.9 & 22.9 & 5.53 & 10.9 & 65 & 92.5 & 26.5 & 4.62 & 20.4 \\
\hline 31 & 48.1 & 25.8 & 5.52 & 11.5 & 66 & 93.0 & 28.2 & 4.57 & 20.6 \\
\hline 32 & 48.8 & 23.5 & 5.52 & 11.5 & 67 & 95.0 & 28.1 & 4.69 & 19.9 \\
\hline 33 & 49.6 & 24.7 & 5.76 & 10.7 & 68 & 101.0 & 27.5 & 4.31 & 24.6 \\
\hline 34 & 49.6 & 25.1 & 5.44 & 11.7 & 69 & 102.0 & 27.8 & 4.50 & 22.8 \\
\hline 35 & 50.2 & 25.0 & 5.75 & 11.1 & 70 & 105.0 & 29.1 & 4.50 & 22.8 \\
\hline
\end{tabular}


As for the reverse extrusion tests, at least five experiments were conducted on each soil sample at varying moisture contents. The extrusion pressure versus water content data pairs at the time of failure were plotted as shown in figure 5. The best fit curve for the data pairs was drawn upon visual inspection for each soil sample. The y-intercept (the coefficient a) and the slope (the coefficient b) of the best fit curve were determined for all 70 soil samples. These reverse extrusion coefficients (i.e. $a$ and $b$ values) for each soil were presented in table 1 . The major reason for establishing the y-intercept and the slope of extrusion pressure versus water content plots is to analytically determine the spesific values of extrusion pressures at plastic and liquid limits.
The extrusion pressures corresponding to the liquid limit values determined from the fall-cone test are calculated using the $\mathrm{a}$ and $\mathrm{b}$ coefficients and listed in table 2. Then, they are plotted as a histogram in figure 6(a). The histograms published by the senior author for the similar purposes are also included in figure 6 for comparison. A close look at figure 6(a) reveals that there is not a distinct range of extrusion pressures dramatically different from the others. Rather, it is observed that most extrusion pressures corresponding to liquid limits fall into a range from 0-30 $\mathrm{kPa}$. To assign a representative extrusion pressure for the liquid limit as was done by Kayabalı and Tüfençki (2010) the arithmetic mean of all extrusion pressure values in this range can be taken, which is aproximately $15 \mathrm{kPa}$. Coincidently, the median value is also $15 \mathrm{kPa}$ for this interval of extrusion pressures.
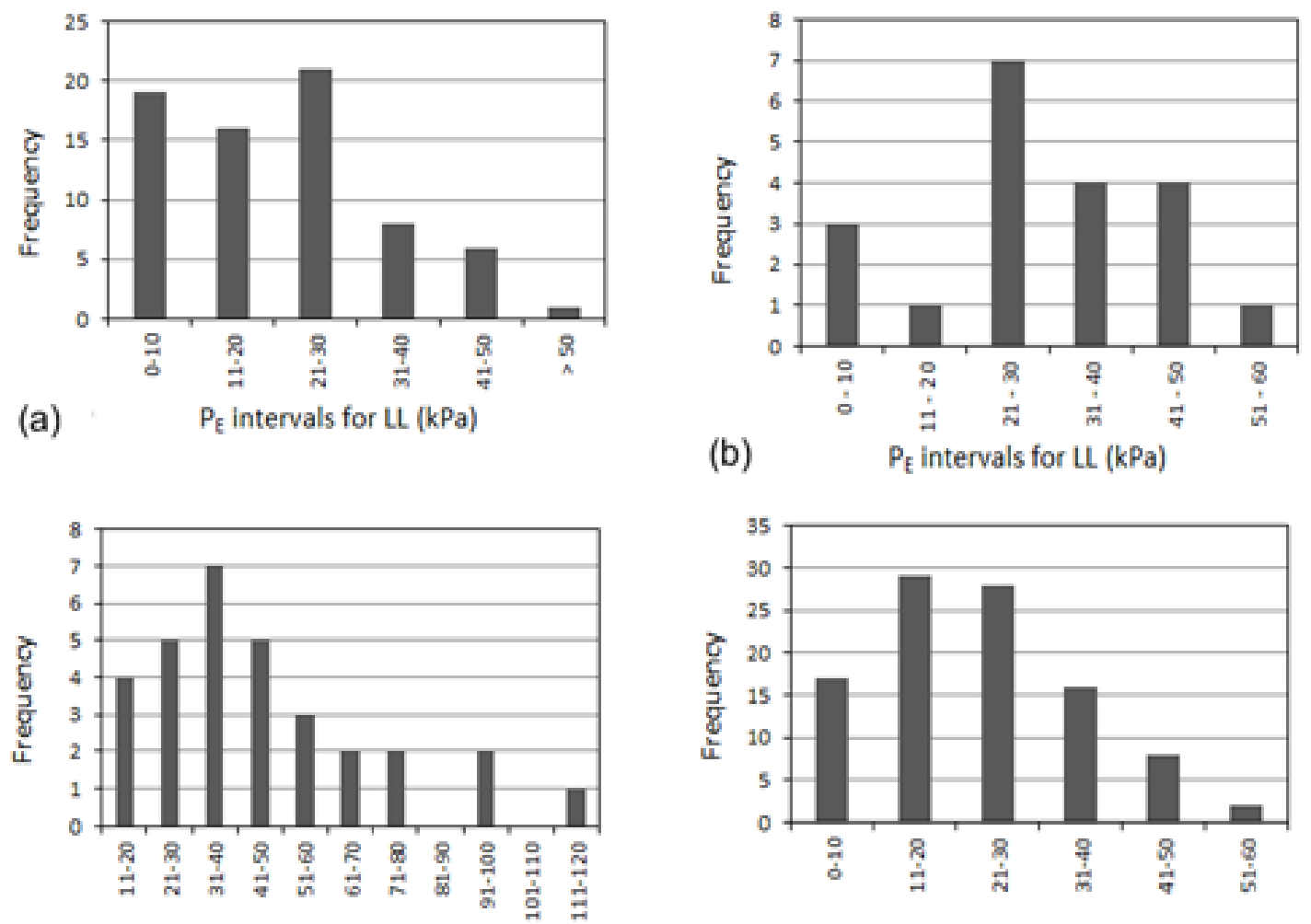

(c)

$P_{E}$ intervals for $\mathrm{LL}(\mathrm{kPa})$

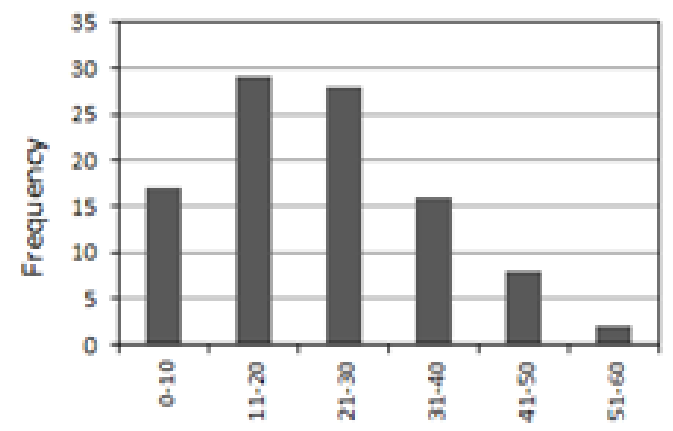

(d)

$\mathrm{P}_{\mathrm{E}}$ intervals for $\mathrm{L}(\mathrm{kPa})$

Figure 6- Extrusion pressure distribution for liquid limit: a) This study, b) from Kayabalı and Tüfenkçi (2007), c) from Kayabalı and Tüfenkçi (2010) and d) from Kayabalı (2012).

In order to predict the liquid limit using the representative extrusion pressure of $15 \mathrm{kPa}$ determined above, a series of computations were carried out using the $\mathrm{a}$ and $\mathrm{b}$ coefficients. The results are listed in table 2. The liquid limit values predicted using the representative extrusion pressure of $15 \mathrm{kPa}$ versus the original liquid limit values determined from the fall-cone test are plotted in figure 7 which 
yields a moderately good coefficient of regression $\left(\mathrm{R}^{2}=0.62\right)$. It is observed that the liquid limit can be predicted with a great success up to 70 ; beyond that, the predicted LL becomes increasingly smaller as the measured LL increases. The most likely reason for this deviation is the fact that the extrusion pressure corresponding to the liquid limit is not the same for all soils.

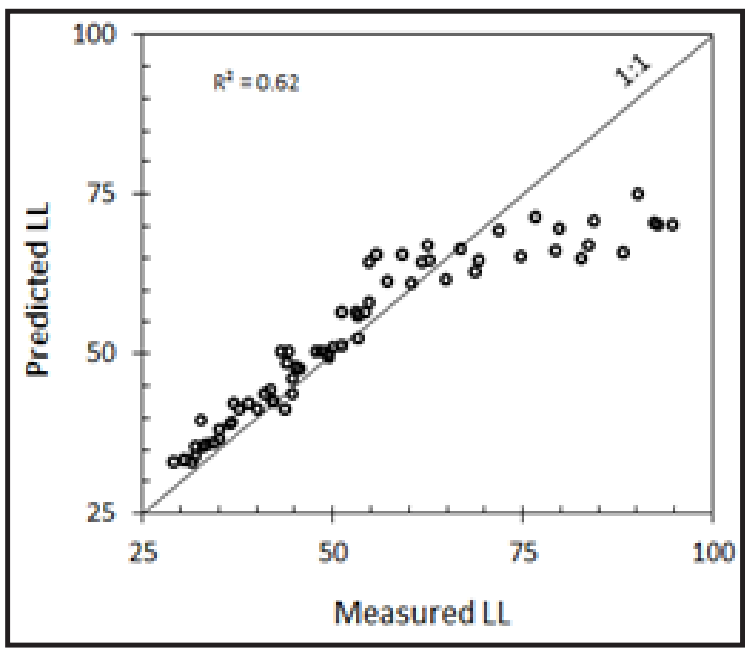

Figure 7- The predicted liquid limits using the representative extrusion pressure of $15 \mathrm{kPa}$ versus the liquid limits determined from fall-cone method.
The extrusion pressures corresponding to the plastic limits determined from the rolling-device method were calculated using the $\mathrm{a}$ and $\mathrm{b}$ coefficients as well. The newly predicted plastic limits are listed in table 2 . Then, the predicted plastic limits are grouped into certain intervals to constitute a histogram in figure $8(\mathrm{a})$, which also includes previously published histograms of similar nature by the senior author for comparison purposes. It is observed that the extrusion pressures corresponding to plastic limits from the rolling-device method predicted using the $\mathrm{a}$ and $\mathrm{b}$ coefficients fall mostly into the interval of 2000-2500 $\mathrm{kPa}$; the mean of the extrusion pressures in this interval is approximately $2300 \mathrm{kPa}$. Using this representative value of $2300 \mathrm{kPa}$ along with the two coefficients, plastic limits for each sample were predicted and listed in table 2. A correlation between the predicted plastic limits using the representative extrusion pressure of $2300 \mathrm{kPa}$ and plastic limits from the rolling-device method is obtained with a moderate value of regression coefficent $\left(R^{2}=0.71\right)$ (Figure 9). The degree of scatter around the plastic limit values of about 24-28 appears to be high; which is also considered to be the results of assuming that the extrusion pressure corresponding to plastic limit is the same for all soils.
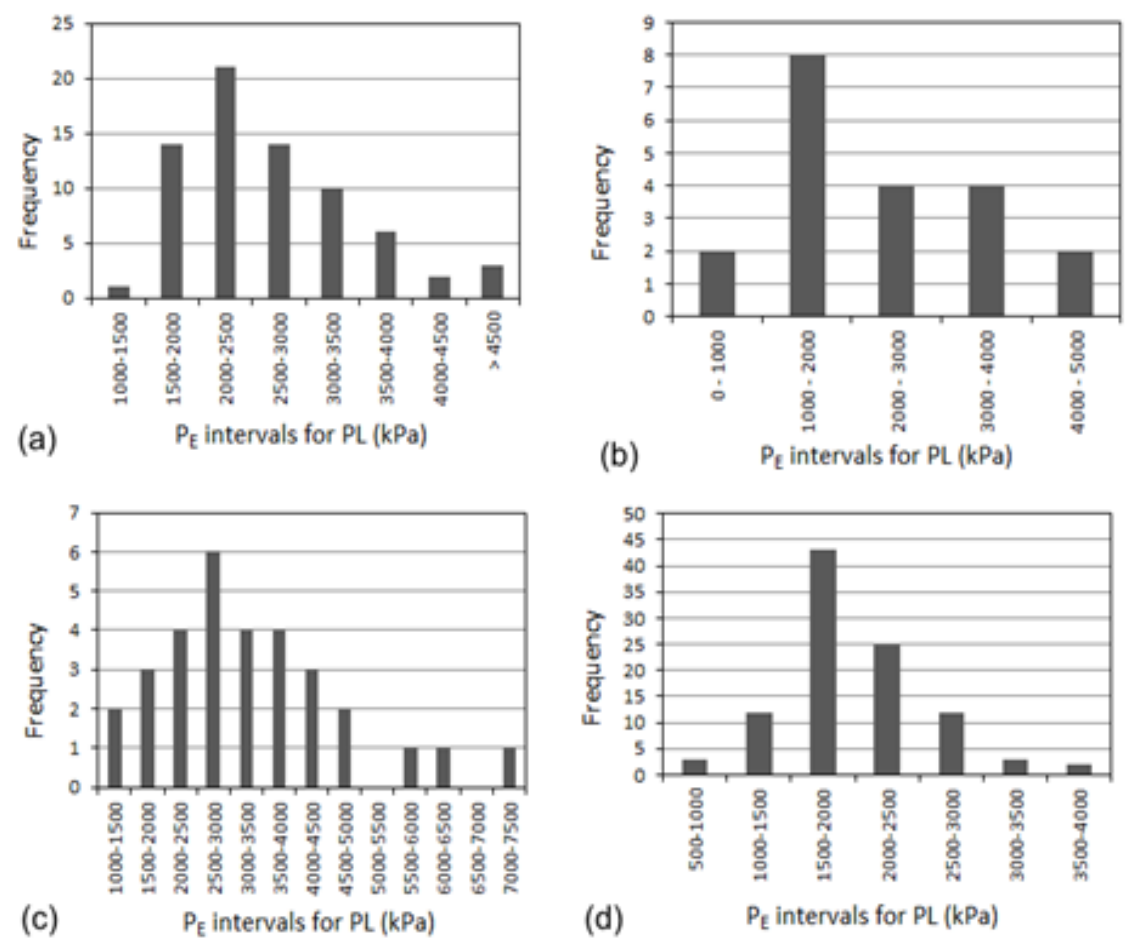

Figure 8- Extrusion pressure distribution for plastic limit: a) This study, b) from Kayabalı and Tüfenkçi (2007), c) from Kayabalı and Tüfenkçi (2010) and d) from Kayabalı (2012). 
Table 2- The computed extrusion pressures for liquid limit $\left[\mathrm{P}_{\mathrm{E}(\mathrm{LL})}\right]$ and plastic limit $\left[\mathrm{P}_{\mathrm{E}(\mathrm{PL})}\right]$, the predicted liquid limit and plastic limit using the representative extrusion pressures $\left(\mathrm{LL}_{\mathrm{PE}=15 \mathrm{kPa}}\right.$ and $\mathrm{PL}_{\mathrm{PE}=2300 \mathrm{kPa}}$ ), the predicted liquid limit and plastic limit using the reverse extrusion coefficients in the empirical relationships $\left(\mathrm{LL}_{\mathrm{a \& b}}\right.$ and $\left.\mathrm{PL}_{\mathrm{a \& b}}\right)$, and the amount of errors involved in predicting LL and PL with the empirical relationships (DLL and DPL).

\begin{tabular}{|c|c|c|c|c|c|c|c|c|}
\hline No. & $P_{E(L L)}(k P a)$ & $P_{E(P L)}(k P a)$ & $\mathbf{L L}_{\mathrm{PE}=15 \mathrm{kPa}}$ & $\mathrm{PL}_{\mathrm{PE}=2300 \mathrm{kPa}}$ & $\mathbf{L} \mathbf{L}_{\mathrm{a} \& \mathrm{~b}}$ & $\mathbf{P L}_{\mathbf{a} \& b}$ & DLL (\%) & DPL (\%) \\
\hline 1 & 50 & 3529 & 32.8 & 18.1 & 35.9 & 17.2 & 22.5 & 2.0 \\
\hline 2 & 33 & 3919 & 33.1 & 18.0 & 34.9 & 17.1 & 13.5 & 4.1 \\
\hline 3 & 31 & 5347 & 33.0 & 17.9 & 34.7 & 17.0 & 12.5 & 10.4 \\
\hline 4 & 23 & 3833 & 32.9 & 18.0 & 35.2 & 17.1 & 11.3 & 3.6 \\
\hline 5 & 36 & 3951 & 35.1 & 18.7 & 35.2 & 17.7 & 9.2 & 4.5 \\
\hline 6 & 24 & 2219 & 33.7 & 18.0 & 34.0 & 17.0 & 5.7 & 5.9 \\
\hline 7 & 67 & 2527 & 39.3 & 17.7 & 31.3 & 17.2 & 4.9 & 0.4 \\
\hline 8 & 27 & 3603 & 35.1 & 18.7 & 35.2 & 17.7 & 5.9 & 2.7 \\
\hline 9 & 28 & 3009 & 35.6 & 19.0 & 35.8 & 18.0 & 6.9 & 0.7 \\
\hline 10 & 23 & 3285 & 35.9 & 19.7 & 38.4 & 18.7 & 11.2 & 0.6 \\
\hline 11 & 21 & 4046 & 36.3 & 20.1 & 39.4 & 19.1 & 12.0 & 4.2 \\
\hline 12 & 30 & 2891 & 37.9 & 18.9 & 34.0 & 17.9 & 3.7 & 0.4 \\
\hline 13 & 26 & 3285 & 38.8 & 20.2 & 37.5 & 19.1 & 1.9 & 1.1 \\
\hline 14 & 26 & 5438 & 39.0 & 20.9 & 39.6 & 19.7 & 7.0 & 10.9 \\
\hline 15 & 45 & 2676 & 42.1 & 19.8 & 35.7 & 19.0 & 3.9 & 0.7 \\
\hline 16 & 34 & 2867 & 41.2 & 20.4 & 37.2 & 19.4 & 1.6 & 0.7 \\
\hline 17 & 31 & 3919 & 42.0 & 21.7 & 40.3 & 20.4 & 3.4 & 4.8 \\
\hline 18 & 18 & 4405 & 41.1 & 21.6 & 40.6 & 20.4 & 0.7 & 6.8 \\
\hline 19 & 26 & 2692 & 43.5 & 21.7 & 40.1 & 20.5 & 2.7 & 2.2 \\
\hline 20 & 24 & 2839 & 44.1 & 21.0 & 38.5 & 20.0 & 8.2 & 0.2 \\
\hline 21 & 16 & 2752 & 42.4 & 22.0 & 41.3 & 20.8 & 2.2 & 2.4 \\
\hline 22 & 15 & 2324 & 42.4 & 21.6 & 40.2 & 20.5 & 5.3 & 5.3 \\
\hline 23 & 46 & 1954 & 49.9 & 20.9 & 41.7 & 20.8 & 4.2 & 4.7 \\
\hline 24 & 6.3 & 5150 & 41.0 & 23.8 & 49.0 & 22.7 & 11.4 & 7.9 \\
\hline 25 & 34 & 2188 & 48.3 & 22.9 & 43.7 & 21.9 & 1.0 & 5.6 \\
\hline 26 & 45 & 3311 & 50.0 & 24.8 & 48.2 & 23.5 & 8.3 & 2.0 \\
\hline 27 & 19 & 2399 & 46.0 & 20.9 & 39.1 & 20.2 & 12.8 & 2.3 \\
\hline 28 & 10 & 2512 & 43.4 & 23.7 & 46.2 & 22.4 & 2.7 & 4.3 \\
\hline 29 & 25 & 3230 & 47.8 & 24.4 & 46.7 & 23.0 & 3.2 & 0.8 \\
\hline 30 & 21 & 2686 & 47.5 & 23.6 & 44.9 & 22.4 & 2.1 & 2.4 \\
\hline 31 & 22 & 1890 & 50.0 & 24.8 & 48.2 & 23.5 & 0.2 & 9.1 \\
\hline 32 & 19 & 2996 & 50.0 & 24.8 & 48.2 & 23.5 & 1.3 & 0.2 \\
\hline 33 & 13 & 2829 & 49.0 & 25.7 & 50.1 & 24.1 & 1.0 & 2.3 \\
\hline 34 & 16 & 1971 & 49.9 & 24.3 & 47.1 & 23.1 & 5.0 & 8.1 \\
\hline 35 & 17 & 3146 & 50.8 & 26.5 & 52.4 & 24.9 & 4.4 & 0.3 \\
\hline 36 & 33 & 2209 & 56.2 & 26.1 & 54.6 & 25.0 & 6.1 & 5.1 \\
\hline 37 & 14 & 3471 & 51.0 & 25.9 & 50.8 & 24.4 & 1.3 & 2.3 \\
\hline 38 & 25 & 3466 & 56.2 & 26.1 & 54.6 & 25.0 & 2.7 & 5.7 \\
\hline 39 & 22 & 2533 & 55.7 & 26.2 & 54.3 & 25.0 & 1.5 & 2.5 \\
\hline 40 & 12 & 2399 & 52.2 & 26.0 & 51.6 & 24.6 & 3.5 & 4.8 \\
\hline 41 & 20 & 2375 & 56.3 & 25.5 & 54.0 & 24.6 & 1.0 & 2.8 \\
\hline 42 & 47 & 2366 & 64.1 & 24.1 & 66.1 & 25.2 & 20.2 & 5.3 \\
\hline 43 & 23 & 2344 & 57.8 & 25.0 & 55.2 & 24.5 & 0.4 & 1.6 \\
\hline
\end{tabular}


Table 2- (continued)

\begin{tabular}{|c|c|c|c|c|c|c|c|c|}
\hline 44 & 48 & 1904 & 65.3 & 24.5 & 69.1 & 25.6 & 23.5 & 1.6 \\
\hline 45 & 25 & 2191 & 61.1 & 25.1 & 60.4 & 25.1 & 5.1 & 1.3 \\
\hline 46 & 30 & 1733 & 65.3 & 23.1 & 68.9 & 25.0 & 16.0 & 2.1 \\
\hline 47 & 15 & 3354 & 60.6 & 27.2 & 61.6 & 26.3 & 1.8 & 6.4 \\
\hline 48 & 20 & 2574 & 64.0 & 26.8 & 67.0 & 26.6 & 8.1 & 2.2 \\
\hline 49 & 24 & 2134 & 66.9 & 24.7 & 72.9 & 26.0 & 16.2 & 2.7 \\
\hline 50 & 18 & 2626 & 64.3 & 25.4 & 67.0 & 25.9 & 6.4 & 6.0 \\
\hline 51 & 8.7 & 2467 & 61.3 & 27.0 & 62.4 & 26.2 & 4.1 & 1.0 \\
\hline 52 & 13 & 1946 & 66.0 & 24.7 & 70.8 & 25.9 & 5.7 & 0.9 \\
\hline 53 & 6.1 & 3178 & 62.5 & 26.7 & 64.2 & 26.3 & 6.9 & 7.6 \\
\hline 54 & 7.5 & 2471 & 64.3 & 26.4 & 67.3 & 26.4 & 3.1 & 1.9 \\
\hline 55 & 11 & 2127 & 69.2 & 25.0 & 79.4 & 26.6 & 10.3 & 3.7 \\
\hline 56 & 4.0 & 2470 & 65.0 & 26.9 & 69.1 & 26.8 & 7.8 & 1.5 \\
\hline 57 & 8.0 & 1946 & 71.3 & 25.4 & 86.0 & 27.3 & 11.7 & 1.3 \\
\hline 58 & 2.6 & 2309 & 65.8 & 26.4 & 70.6 & 26.7 & 11.2 & 1.0 \\
\hline 59 & 4.4 & 1888 & 69.4 & 26.1 & 79.9 & 27.2 & 0.1 & 2.2 \\
\hline 60 & 1.2 & 2257 & 64.5 & 27.2 & 68.3 & 26.8 & 17.7 & 1.7 \\
\hline 61 & 1.7 & 2233 & 66.7 & 26.5 & 72.8 & 26.8 & 13.3 & 0.5 \\
\hline 62 & 3.2 & 2134 & 70.7 & 25.4 & 84.0 & 27.1 & 0.6 & 4.0 \\
\hline 63 & 0.8 & 2056 & 65.6 & 25.8 & 70.0 & 26.3 & 20.9 & 1.5 \\
\hline 64 & 3.2 & 1574 & 74.9 & 24.0 & 100.8 & 27.5 & 11.4 & 1.2 \\
\hline 65 & 1.2 & 2094 & 70.3 & 25.7 & 82.7 & 27.2 & 10.6 & 2.5 \\
\hline 66 & 1.1 & 1589 & 69.9 & 24.9 & 81.8 & 26.7 & 12.1 & 5.2 \\
\hline 67 & 0.8 & 1896 & 69.9 & 26.4 & 81.5 & 27.5 & 14.2 & 2.3 \\
\hline 68 & 1.6 & 1556 & 77.1 & 23.3 & 111.9 & 27.8 & 10.8 & 1.0 \\
\hline 69 & 1.1 & 1909 & 75.8 & 26.0 & 102.7 & 28.5 & 0.7 & 2.5 \\
\hline 70 & 0.8 & 1674 & 75.8 & 26.0 & 102.7 & 28.5 & 2.2 & 2.1 \\
\hline
\end{tabular}

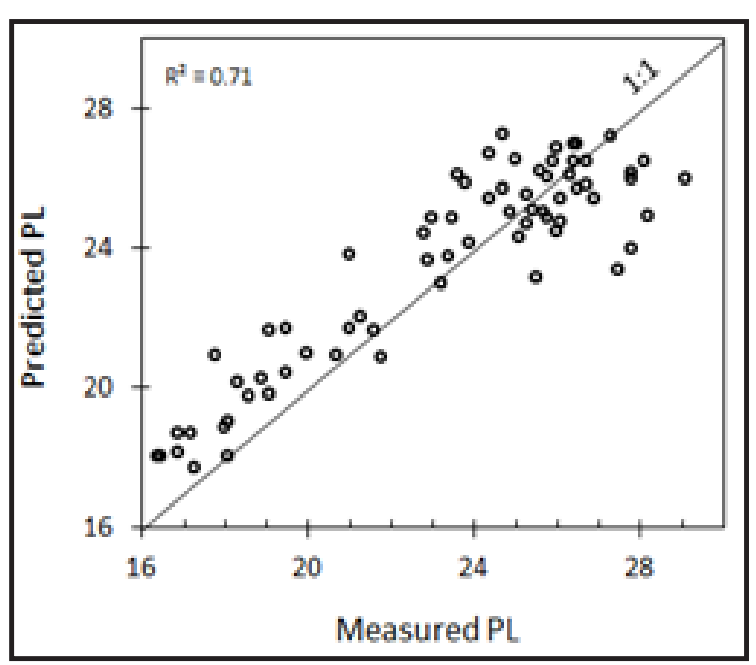

Figure 9- The predicted plastic limits using the representative extrusion pressure of $2300 \mathrm{kPa}$ versus the plastic limits determined from rolling-device method.
Both regression coefficients for the correlations between the representative extrusion pressures from the reverse extrusion test and the liquid limits from the fall-cone method and the plastic limits from the rolling-device method, respectively, are rather encouraging; however, the authors' perception is that neither the correlation between the predicted and laboratory-determined liquid limits nor the correlation between the predicted and the laboratory-determined plastic limits can be utilized for practical purposes because the amounts of error involved in both predictions would be unacceptably high. The most likely reason for the imperfect match between the predicted- and laboratory-determined Atterberg limits are the variations of predominant range of extrusion pressures in histograms of figures 6 and 8 . For instance, the predominant intervals for the extrusion pressures corresponding to liquid limits are $21-30 \mathrm{kPa}$ for this study, 21-30 kPa for Kayabalı and Tüfenkçi 
(2007) data, 31-40 kPa for Kayabalı and Tüfenkçi (2010) data and 11-20 kPa for Kayabalı (2012) data (Figure 6). The range of plasticity for soils used in this investigation and those in the previously published papers are not the same. Apparently, the extrusion pressures are plasticity dependent; for instance, while the soil samples with liquid limits higher than 75 have extrusion pressures corresponding to liquid limits less than $5 \mathrm{kPa}$, the soil samples with liquid limits around 30 or so have extrusion pressures corresponding liquid limits greater than roughly $30 \mathrm{kPa}$, indicating that the extrusion pressures corresponding liquid limits of low-plastic soils may be as high high as ten times that the extrusion pressures corresponding to liquid limits of high-plastic soils (see, for instance, table 1).

A similar conclusion can be drawn from figure 8 , where the predominant intervals of extrusion pressures corresponding to the experimentally determined plastic limits are $2000-2500 \mathrm{kPa}$ for this study, 1000-2000 kPa for Kayabalı and Tüfenkçi (2007) data, 2500-3000 kPa for Kayabalı and Tüfenkçi (2010) study and 1500-2000 kPa for Kayabalı (2012) data. There is not a unique extrusion pressure to represent soils' plastic limit either. The bottomline is that assigning a single extrusion pressure value for all liquid limits is not realistic; the same is true for plastic limit.

In an attempt to seek a more meaningful relationship between the reverse extrusion characteristics of fine-grained soils and consistency limits a multiple regression analysis was carried out. For this purpose the liquid limit or the plastic limit were tried to be determined to be the functions of reverse extrusion coefficients (i.e., a and b).

The multiple regression between the reverse extrusion coefficients and the liquid limits determined using the fall-cone method resulted in the following empirical relationship with $\mathrm{R}^{2}=0.92$ :

$$
\mathrm{LL}=0.04\left(\mathrm{a}^{3.3}\right) 1.135^{\mathrm{b}}
$$

Likewise, the multiple regression analysis between the reverse extrusion coefficients and the plastic limits determined using the rolling-device method yield the following empirical relationship with $\mathrm{R}^{2}=0.94$ :

$$
\mathrm{PL}=0.04\left(\mathrm{a}^{2.33}\right) \mathrm{b}^{0.98}
$$

At the next step the liquid and plastic limits are predicted with the empirical relationships given by equations (1) and (2), respectively. For instance, the liquid limit of any soil sample can be predicted by plugging the reverse extrusion coefficients of that soil sample into Eq. (1). Table 2 includes liquid limits and plastic limits for all soil samples predicted by the empirical relationships given in Eq. (1) and (2).

Figure 10 illustrates the correlation between the predicted liquid limit by Eq. (1) and the liquid limit determined through the fall-cone method. The matching of the predicted data with the laboratory data is superior (with $\mathrm{R}^{2}=0.91$ ) to the correlation between the liquid limits predicted by the representative extrusion pressure of $15 \mathrm{kPa}$ (Figure 7). It appears that there is some scatter of data pairs in figure 10. One possible reason for this may be due to the uncertainties inherent to the fall-cone test itself. Further analyses may be required to asses this thoroughly. The correlation between the predicted PL using the reverse extrusion coeeficients [i.e., Eq. (2)] provided better matching with the laboratory data from the rolling-device (see Figure $11 ; \mathrm{R}^{2}=0.91$ ) than that did the representative extrusion pressure of $2300 \mathrm{kPa}$ (Figure 9).

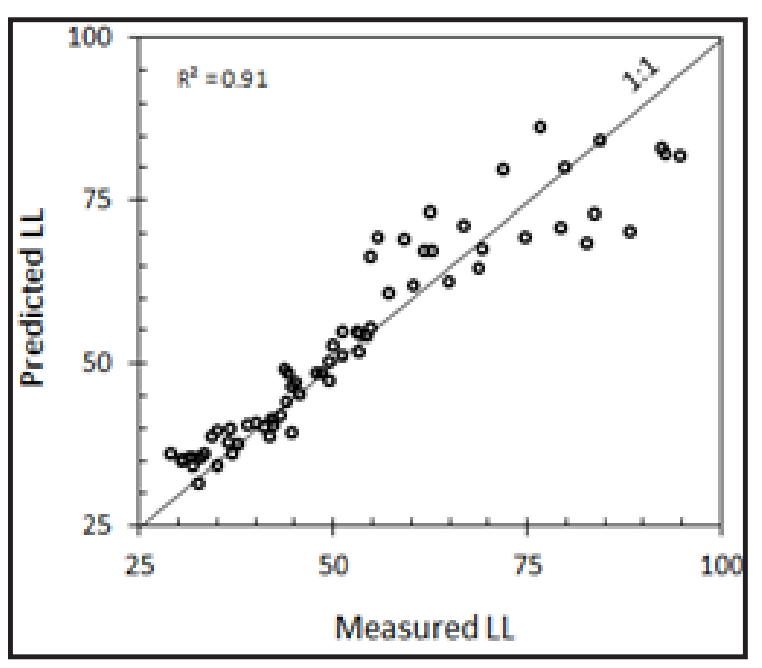

Figure 10- The predicted liquid limits using Eq. (1) versus versus the liquid limits determined from fallcone method.

In order to assess the ability of the newly proposed equations to predict the liquid limit and plastic limit, a series of error analysis was performed. For instance, the amount of error involved in predicting the liquid limit with the proposed relationship (i.e., Eq. 1) was 


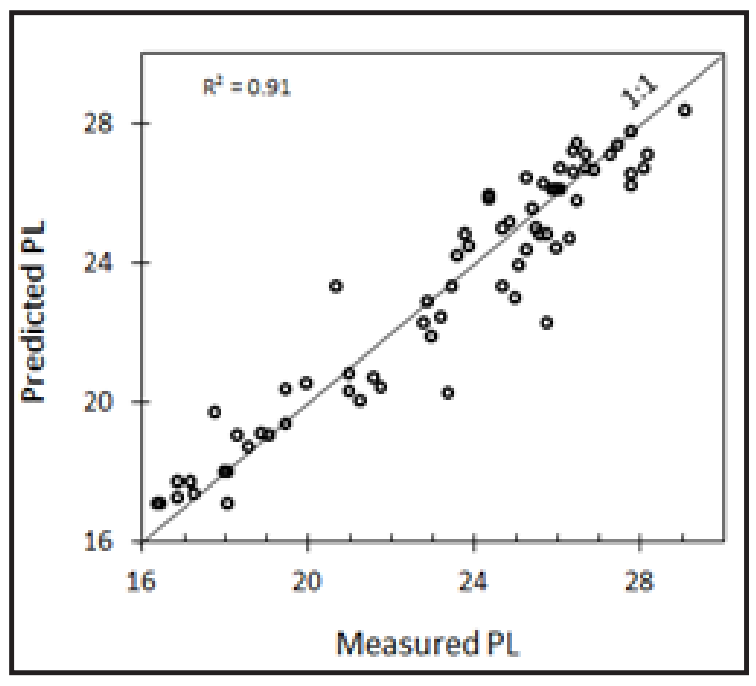

Figure 11- The predicted plastic limits using Eq. (2) versus versus the plastic limits determined from rollingdevice method.

calculated as the ratio of the absolute value of the difference between the experimentally determined value and the predicted value to the experimentally determined value. The results are presented in table 2 as percentages. The same approach was employed to calculate the amounts of error for plastic limit and the results were listed in table 2.

To examine the distribution of percent errors for predicting the liquid limit the histogram in figure 12 was constructed. It is observed that more than $70 \%$ of experimentally determined liquid limits were predicted with an error less than $10 \%$. The mean of all error values is $7.2 \%$ with a standard deviation of $5.8 \%$. The percent error distribution for the plastic

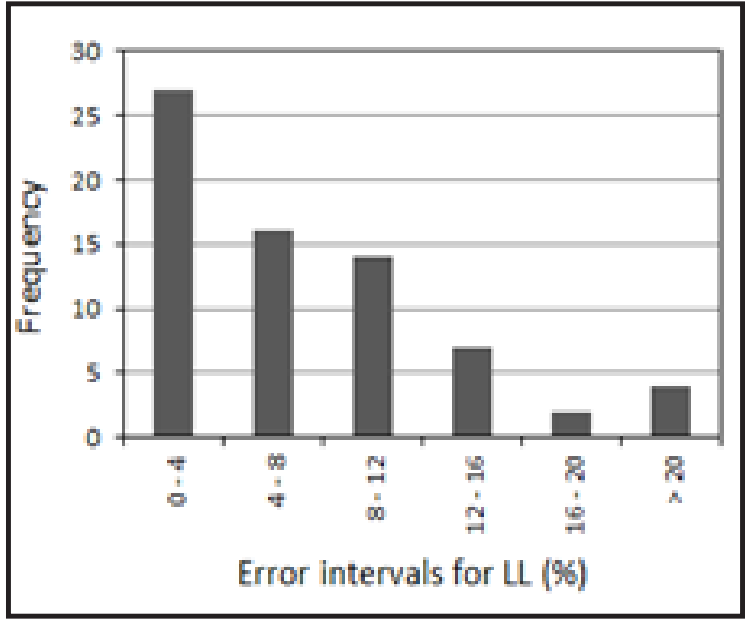

Figure 12- Percent error distribution for the predicted liquid limits using Eq. (1) with respect to the liquid limits determined from fall-cone method. limit is shown in figure 13 as a histogram. The ability of the newly proposed equation to predict the plastic limit using the reverse extrusion coefficients appears to be remarkably good. About all plastic limits were predicted with an error of $10 \%$ and more than $80 \%$ of the plastic limits obtained from the rolling-device method can be found with a $\pm 5 \%$ error.

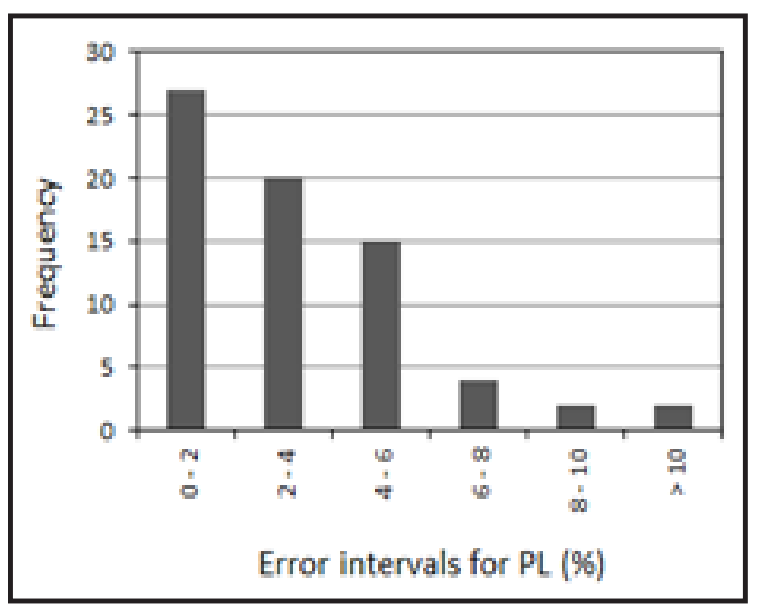

Figure 13- Percent error distribution for the predicted plastic limits using Eq. (2) with respect to the plastic limits determined from rolling-device method.

\section{Conclusions}

Following conclusions were drawn from this investigation:

1) The liquid limits and plastic limits predicted using the representative extrusion pressures of 15 $\mathrm{kPa}$ and $2300 \mathrm{kPa}$ for the liquid limit and plastic limit, respectively, yield moderate- to good-level of correlations with the experimentally-determined consistency limits.

2) The imperfect match between the predicted consistency limits using the representative extrusion pressures and the experimentally determined consistency limits are attributed to the fact that the extrusion pressure corresponding to liquid limit is not constant for all soils. The same is true for plastic limit. It was observed that the extrusion pressures at either liquid limit or plastic limit for low-plasticity soils are many times those of high-plasticity soils. Therefore, the selection of representative extrusion pressures for liquid limit and plastic limit for the definition of those consistency limits proved not to be a good reference.

3) An alternative using the coefficents obtained from the fitted curves to the extrusion pressure versus water content data (i.e. a and b) in a multiple regression analysis showed that there exists a very 
good level of correlation between the reverse extrusion coefficents and the two consistency limits.

4) The success obtained from a new series of predictions using the emprical equations using the multiple regression analysis is much better. The average of absolute errors for plastic limit and liquid limit are $3 \%$ and $7 \%$, respectively.

5) The previous researchers indicated that the reverse extrusion test is robust, simple and highly inexpensive method. This fact is confirmed herein and it is proposed that the reverse extrusion method can be reliably used for the prediction of two of the most commonly used consistency limits together.

6) The proposed method is limited to the soils with the liquid limit range of 29-105. Precaution should be taken when applied to soils outside this range. Further analyses are recommended to cover the soils of very low plasticity as well as very high plasticity.

Received: 02.09.2014 Accepted: 15.02.2015

Published: June 2015

\section{References}

American Society for Testing Materials, 2010. Standard test methods for liquid limit, plastic limit, and plasticity index of soils: ASTM D4318-10, West Conshohocken, PA.

Belviso, R., Ciampoli, S., Cotecchia, V., and Federico, A., 1985. Use of the cone penetrometer to determine consistency limits. Ground Engineering, 18(5), 2122.

BSI, 1990. Methods of test for civil engineering purposes classification tets (BS1377-2): British Standard Institution (BSI), London, UK.

CAN/BNQ, 1986. Soils - determination of liquid limit by the Swedish fall-cone penetrometer method and determination of plastic limit: CAN/BNQ 2501-092M-86, Canadian Standards Asspciation and Bureau de Normalization du Quebec, Rexdale, Ont.

Casagrande, A, 1932. Research on the Atterberg limits of soils: Public Roads, 13, 3, 121-130.

Casagrande, A, 1958. Notes on the design of liquid limit device: Geotechnique, 8, 2, 84-91.

Clayton, C. R. I., Matthews, M. C. and Simons, N. E., 1995, Site investigation: Blackwell Science, $584 \mathrm{p}$.

Dolinar, B., 2010. Predicting the normalized, undrained shear strength of saturated fine-grained soils using plasticity-value correlations: Applied Clay Science, 47, 428-432.

Haigh, S. K., 2012. Mechanics of the Casagrande liquid limit test: Canadian Geotechnical Journal, 49, 1015-1023.
ISI, 1985. Determination of liquid and plastic limits (2270)I In Indian Standard Method of Test for Soils, Part 5, Indian Standards Institution (ISI), New Delhi, India.

Johnston, M. M., Strom, W. E. Jr., 1968. Results of second division laboratory testing program on standard soil samples: Misc. Paper, 3-978, U.S. army Engineer Waterways Experiment Station, Vicksburg, MS.

Kayabal1, K., 2012. An alternative testing tool for plastic limit: Electronic Journal of Geotechnical Engineering 17(O), 2107-2114.

Kayabalı, K., Tüfenkçi, O. O., 2007. A different perspectıve for the determination of soil consistence limits: International Symposium on Geotechnical Engineering, Ground Improvement and Geosynthetics for Human Security and Environmental Preservation, Bangkok, Thailand, 423-432.

Kayabalı K., Tüfenkçi, O. O., 2010. Determination of plastic and liquid limits using the reverse extrusion technique: Geotechnical Testing Journal 33(1), 1422.

Lee, L. T., Freeman, R. B., 2007. An alternative test method for assessing consistency limits. Geotechnical Testing Journal, 30(4), 1-8.

Medhat, F., Whyte, I. L., 1986. An appraisal of soil index tests. Geological Society, Engineering Geology Special Publication 2, 317-323.

Prakash, K., Sridharan, A., 2006. Critical appraisal of the cone penetration method of determining soil plasticity. Can. Geotech. J. 43, 884-888.

Sherwood, P. T., 1970. The reproducibility of the results of soil classification and compaction tests: Report LR 339, Crowthorne, Road Research Laboratory.

Sherwood, P. T., Ryley, M. D., 1970. An investigation of a cone-penetrometer method for the determination of the liquid limit. Geotechnique, 20, 2, 203-208.

Sivakumar, V., Glynn, D., Cairns, P., Black, J. A., 2009. A new method of measuring plastic limit of fine materials. Geotechnique, 59, 10, 813-823.

Timar, A., 1974. Testing the plastic properties of cohesive and intermediate-type soils by extrusion. Acta Tech. Ac. Sci. Hungary 76 (3-4), 355-370.

Wasti, Y., Bezirci, M. H., 1986. Determination of the consistency limits of soils by the fall-cone test. Canadian Geotechnical Journal 23, 241-246.

Whyte, I. L., 1982. Soil plasticity and strength - a new approach for using extrusion. Ground Engineering, 15(1), 16-24.

Wood, D. M., 1982. Cone penetrometer and liquid limits. Geotechnique, 32, 2, 152-157.

Wroth, C. P., Wood, D. M., 1978. The correlation of index properties with some basic engineering properties of soils. Canadian Geotechnical Journal 15(2), $137-$ 145 . 
